\title{
Saskatchewan regulation breach linked to pathologist shortage
}

A breach of Saskatchewan's medical laboratory licensing regulations by the Saskatoon Health Region, exposed by a whistleblower who has since been fired, has been linked to the region's shortage of pathologists - a problem noticeable across Canada.

Dr. Kirk Ready, an anatomical pathologist, was dismissed without cause by the Saskatoon Health Region in May after he leaked to the media that the region was in breach of provincial regulations that require the director of laboratories to be a physician. The director at the time John Krahn, who has since been replaced with an interim physician director - had held the position for five years but was a $\mathrm{PhD}$ in clinical chemistry.

According to Dr. Martin Trotter, vice president of the Canadian Association of Pathologists, though it is ideal for directors to be physicians because of their experience in all laboratory specialties, people with $\mathrm{PhDs}$ in areas such as medical biochemistry can competently run laboratories if they "delegate expert leadership at the division level to ensure a high-quality service." Indeed, countries including the United States and the United Kingdom, as well as such provinces as Ontario and Alberta, don't require medical laboratory directors to have medical degrees.

The Saskatoon Health Region also requires that its divisional head of anatomical pathology be a physician because $\mathrm{PhD}$ programs don't provide training in this area. The position, however, has been vacant for five years and Krahn had also been acting in that role.

"It becomes virtually fraudulent," says Ready, who is planning to take legal action over his dismissal.

Sandra Blevins, vice president, clinical and operations support for the Saskatoon Health Region, explains the vacancies by saying, "these are very difficult positions to fill."

The region is now four pathologists

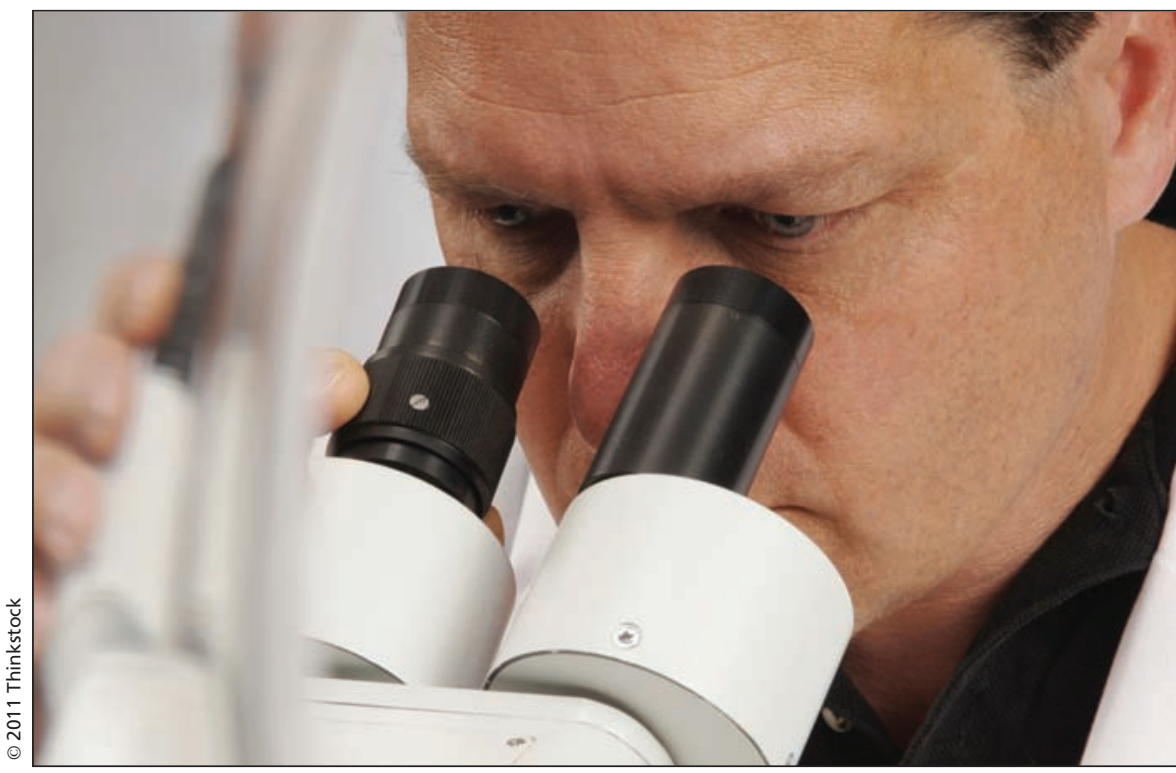

Canadian medical laboratories are struggling to find and retain pathologists, and the number of lab physicians turning 65 is almost double the number of people graduating from pathology training programs.

short and the average turnaround time for reports is 12 days, admits Blevins. By contrast, the standard report time set by the College of American Pathologists ranges from two days for rush biopsies to five days for complex surgical cases. Saskatoon also has a backlog of between 1100 and 1300 cases.

"You're going through the pile and you end up with a skin incision, and you find it's malignant melanoma, and you think, 'Oh shoot, that really should have been dealt with weeks ago'," says Ready, describing his last few weeks on the job.

The overall lack of pathologists in Canada underlies the Saskatoon controversy, says Trotter. The number of lab physicians turning 65 is almost double the number of people graduating from pathology training programs. While the number of family practitioners and clinical medical specialists each increased by more than $6 \%$, the number of laboratory physicians and pathologists decreased by $1.8 \%$ and $1.4 \%$, respectively, from 1998 to 2008, according to research conducted by Dr. Terence Colgan, a pathology pro- fessor at the University of Toronto in Ontario, that is scheduled to be published in a forthcoming issue of The Canadian Journal of Pathology (www.andrewjohn publishing.com/images/PathologyVol31 Colgan.pdf).

The repercussion of the shortage could have disastrous effects on patient care, says Colgan, who suggests "there's reason for us to have concerns going forward, particularly in the area of cancer, which is growing dramatically because of the aging population."

One reason for the low interest in pathology among medical graduates relates to changes in medical school curricula during the past decade, says Trotter. In systems-based teaching models, students no longer take second-year pathology courses. Meanwhile, says Trotter, students are expected to choose specialties in their second or third year, "when they really don't have knowledge of what pathology and laboratory medicine are." - Wendy Glauser, Toronto, Ont.

CMAJ 2011. DOI:10.1503/cmaj.109-3947 